NBER WORKING PAPER SERIES

\title{
RESEARCH AND DEVELOPMENT, UTILIZATION AND LABOR REQUIREMENTS: A DYNAMIC ANALYSIS
}

\author{
Jeffrey I. Bernstein \\ M. Ishaq Nadiri
}

Working Paper No. 1016

\section{NATIONAL BUREAU OF ECONOMIC RESEARCH 1050 Massachusetts Avenue \\ Cambridge MA 02138}

November 1982

\begin{abstract}
We would like to thank members of the NBER workshop on R\&D and Productivity for helpful comments. The research reported here is part of the NBER's research program in Productivity. Any opinions expressed are those of the authors and not those of the National Bureau of Economic Research.
\end{abstract}


NBER Working Paper $\# 1016$

November 1982

Research and Development, Utilization and Labor

Requirements: A Dynamic Analysis

\begin{abstract}
In this study we have developed a dynamic analysis of a firm undertaking plant and equipment and research and development investment, along with labor requirement and P\&E utilization decisions. It is shown that in the short run increases in R\&D cause the utilization rate of plant and equipment to rise and to decrease demand for labor per unit of R\&D. We distinguish between the effects of the stock of R\&D and the investment flow. The short run effect of changes in the stock of R\&D on labor demand are quite distinct from the behavior observed along the intertemporal path. Along the path increases in the R\&D investment rate must be accompanied by an increase in the labor requirement per unit. of R\&D. Contrary to a viewpoint held by many, the R\&D investment flow does not displace labor. Finally, our model provides a framework to justify the empirically observed positive relationship between the utilization and the $\mathrm{P} \& \mathrm{E}$ investment rates.
\end{abstract}

Jeffrey I. Bernstein Department of Economics Carleton University Ottawa, Ontario Canada K1S 5B6

(613) 231-4377
M. Ishaq Nadiri

Department of Economics

New York University 15-19 West 4th Street New York, NY 10012

(212) 598-7042 
1. Introduction

By its very nature research and development (R\&D) alters the level and composition of the outputs supplied and inputs demanded by firms. The empirical work of Edward Denison [1974], Dale Jorgenson and Zvi Griliches [1967], John Kendrick [1973] and M. Ishaq Nadiri and Sherwin Rosen [1973] has characterized how technological change has been a significant element to output growth. Moreover, studies documented by Edwin Mansfield [1972] have come to the conclusion that research and development has been a major determinant of technical progress.

The dynamic theory of investment by firms often ignores the important interplay, both in the short run and intertemporally, between the decisions to accumulate technical knowledge, to utilize and invest in plant and equipment and to hire labor. A major stumbling block has been that the only variable input is generally labor, while plant and equipment utilization is costlessly altered. This structure implies that changes in the level of research and development only affect factor proportions through changes in labor requirements, but not through the utilization of plant and equipment.

In a static framework Paul Taubman and Maurice Wilkinson [1970], Robert Lucas [1970] and Gordon winston and Thomas McCoy [1974] analyzed the role of factor utilization which increases both output and input prices. Recently Andrew Abel [1981] developed a dynamic model where labor utilization is costly and instantaneously determined, while labor and capital are quasi-fixed factors. In this paper we develop a dynamic analysis of the determinants of labor requirements and capital utilization at any point in time given the stocks of both $R \& D$ and plant and equipment (P\&E) capital. The firm alters the level of these stocks through their investment decisions, 
one pertaining to the standard P\&E and the other to R\&D.

In our model we explicitly recognize the dual nature of R\&D. As a flow variable, the investment is part of the short run equilibrium, while as a stock, its level governs the dynamic path of the firm. In the short run we establish that increases in the stock of $R \& D$ relative to the stock of $P \& E$ increase the rate of physical capital utilization and decrease the requirements of labor per unit of the stock of knowledge. Thus the firm becomes less labor intensive in the sense that the rate of $P \& E$ utilization increases at the expense of labor in R\&D intensive form.

The dynamic path exhibits some interesting properties. First is the stock of $P \& E$ relative to the stock of R\&D rises towards its steady state value, the $P \& E$ growth rate decreases. This result occurs due to the presence of convex adjustment costs." When the stock is too low . relative to the long run magnitude, the marginal adjustment costs are too high. This implies that the $P \& E$ growth rate falls towards its steady state rate. Simultaneously, as the stock rises, there is an easing of the pressure on the rate of P\&E utilization and therefore over time it also decreases. Thus we find that along the dynamic path the P\&E growth and utilization rates are positively correlated.

Second, as the stock of P\&E relative to the stock of R\&D rises," the $R \& D$ growth rate increases, because the demand price is too low relative to its steady state value. Combining this conclusion, with the short run result that the expansion of P\&E relative to $R \& D$ displaces 1 abor per unit of $R \& D$, implies that along the dynamic path $R \& D$ investment and labor are positively correlated. 
We develop the structure of the model and the short run equilibrium properties in Section 2. Section 3 is devoted to the dynamic path and steady state characteristics. In Section 4 some comparative long run results are discussed and then we conclude.

\section{The Mode1}

In order to model the role of R\&D and its interaction with the other two factors of production, plant and equipment services and labor services, we assume that the firm's production process is represented as

$$
y(t)=F\left[\beta(t) K_{p}(t), K_{r}(t), L(t)\right]
$$

where $y(t)$ is output, $F$ is the twice continuously differentiable production function, $\beta(t)$ is the index of $P \& E$ utilization, $K_{p}(t)$ is the stock of $P \& E, K_{r}(t)$ is the stock of $R \& D$ and $L(t)$ is labor services. All variables are evaluated at time $t .{ }^{1}$ The marginal products are positive and diminishing for each of the factors.

The physical capital utilization rate can be thought of as an index of plant and equipment usage at each time period. In our model, the stocks of $P \& E$ and $R \& D$ are quasi-fixed factors while labor requirements and the P\&E utilization rate are variable in the short run.

R\&D essentially affects the production process in two ways. First it alters the nature of the factors of production. Indeed it seems appropriate to view the services of plant and equipment and labor in relation to the existing sţock of knowledge. This implies that it is $k_{p}(t)=K_{p}(t) / K_{r}(t)$ and $\ell(t)=L(t) / K_{r}(t)$, along with the $P \& E$ utilization rate which governs production. 
Si Ind, if the technology exhibits constant returns to scale, then knowledge, as well as physical capital and labor services, must all increase by the same proportion in order to generate an equal percentage increase in output. Thus if the stock of knowledge is fixed, we would expect diminishing returns to the two other factors of production ( $\beta K_{p}$ and L). We can incorporate these stylized facts by assuming that the production function, $F$, is homogeneous of degree 1 in $\beta(t) K_{p}(t), K_{r}(t)$ and $L(t)$. Hence

$$
y(t)=K_{r}(t) f\left[\beta(t) k_{p}(t), l(t)\right]
$$

The endogeneity of the $P \& E$ utilization rate permits physical capital to be operated at various times. Clearly labor prefers certain times to others, as the major portion of factories and machines are operated in the daytime and during the Wek. Thus in order to attract workers to overtime, night and weekend shifts, a premium wage rate must be paid. The wage rate in our model consists of two components, the fixed scale or basic rate, $s$, and the premium rate, $\omega(B)$, which is an increasing convex function of the P\&E utilization rate. ${ }^{2}$

The flow of funds for the firm is

$$
F=p y-s \omega(\beta) L-C\left(I_{p} / K_{p}\right) I_{p}-E\left(I_{r} / K_{r}\right) I_{r},
$$

where $\mathrm{p}$ is the fixed product price. ${ }^{3}$ The costs of installing additional $\mathrm{P} \& \mathrm{E}$ is $\mathrm{C}$ with $\mathrm{C}^{\prime}>0, \mathrm{C}^{\prime \prime}>0$ for $I_{\mathrm{p}}>0, \mathrm{C}^{\prime} \mathrm{C}^{\prime}=0$ for $I_{p}=0$. The costs of developing additional R\&D is $E$ with $E^{\prime}>0$, $E^{\prime \prime}>0$ for $I_{r}>0, E=E^{\prime}=0$ for $I_{r}=0.4$

In this model the major difference between the stocks of P\&E and $R \& D$ is that there are two costs associated with $P \& E$; utilization [ $\omega(8)]$ and installation $\left[C\left(I_{p} / K_{p}\right)\right]$. However, with respect to $R \& D$, there are 
only development costs associated with additions to the stock of knowledge $\left[\mathrm{E}\left(\mathrm{I}_{\mathrm{r}} / \mathrm{K}_{\mathrm{r}}\right) \mathrm{I}_{\mathrm{r}}\right]$. Once the stock of knowledge exists there are zero costs associated with its utilization.

Knowledge and physical capital are accumulated by

(4)

$$
\begin{aligned}
& \dot{\mathrm{K}}_{\mathrm{p}}=\mathrm{I}_{\mathrm{p}}-\delta \mathrm{K}_{\mathrm{p}} \\
& \dot{\mathrm{K}}_{r}=\mathrm{I}_{r}-\eta \mathrm{K}_{\mathrm{r}}
\end{aligned}
$$

where $0 \leq \delta \leq 1$ is the rate of $P \& E$ depreciation and $0 \leq n \leq 1$ is the rate of R\&D observance.

The firm desires to maximize the present value of the flow of funds, which is discounted at the constant rate $r$, subject to equations (2), (4) and (5). In order to fulfill the objective, the firm selects P\&E utilization, labor and investment while $\mathrm{K}_{\mathrm{p}}, \mathrm{K}_{\mathrm{r}}$ and the associated investment demand prices delimit the dynamic path.

The Hamiltonian of the problem is

$$
\begin{aligned}
H= & p K_{r} f\left(\beta k_{p}, l\right)-s \omega(\beta) L-C\left(I_{p} / K_{p}\right) I_{p}-E\left(I_{r} / K_{r}\right) I_{r} \\
& +q_{1}\left(I_{p}-\delta K_{p}\right)+q_{2}\left(I_{r}-\eta K_{r}\right) .
\end{aligned}
$$

The first order and canonical conditions are

$$
\begin{aligned}
& \text { (7.1) } \frac{\partial H}{\partial L}=p f_{2}-s \omega=0 \\
& \text { (7.2) } \quad \frac{\partial H}{\partial B}=p f_{1} K_{p}-s w^{\prime} L=0 \\
& \text { (7.3) } \quad \frac{\partial H}{\partial I_{p}}=-C^{\prime} \frac{I_{p}}{K_{p}}-C+q_{1}=0
\end{aligned}
$$


(7.4) $\quad \frac{\partial H}{\partial I_{r}}=E^{\prime} \frac{I_{r}}{K_{r}}-E+q_{2}=0$

$$
\dot{q}_{1}=(r+\delta) q_{1}-p f_{1} \beta-C^{\prime}\left(I_{p} / k_{p}\right)^{2}
$$

$$
\dot{\mathrm{K}}_{\mathrm{p}}=\mathrm{I}_{\mathrm{p}}-\delta \mathrm{K}_{\mathrm{p}}
$$

$$
\dot{q}_{2}=(r+n) q_{2}-p f+p f_{1} \beta k_{p}+p f_{2} \ell-E^{\prime}\left(I_{r} / K_{r}\right)^{2}
$$

$$
\dot{\mathrm{K}}_{\mathrm{r}}=\mathrm{I}_{\mathrm{r}}-\mathrm{nK}_{\mathrm{r}} \text {. }
$$

There are also the transversality conditions and the Legendre-clebsch conditions, which state that the matrix of second order derivatives of the control variables is negative definite.

The short run equilibrium of the firm is denoted by (7.1)-(7.4), that is, given the capital stgcks and the investment demand prices $\left(q_{1}\right.$ and $\left.q_{2}\right)$ we can determine the derived demand for labor, the $P \& E$ utilization rate and investment per capital stock for both $P \& E$ and R\&D.

The determination of labor requirements and utilization is simultaneous. In addition, the firm does not determine labor demand, but rather labor relative to $R \& D$. In other words labor in $R \& D$ intensive form is the relevant measure at each time period. To see this divide (7.2) by $\mathrm{K}_{\mathrm{r}}$, then $\mathrm{pf}_{1} \mathrm{k}_{\mathrm{p}}-\mathrm{s} \omega^{\prime} \ell=0$. The latter equation and (7.1) can be solved for $\ell=\mathcal{G}\left(k_{p}, s / p\right), \beta=B\left(k_{p}, s / p\right)$. R\&D intensive labor and the $P \& E$ utilization rate depend on the $R \& D$ intensive stock of $P \& E$ and the real scale wage rate.

$$
\text { Combining equations (7.1) and (7.2), }
$$

$$
\theta=\mathrm{e}_{\beta} / \mathrm{e}_{\ell}
$$


where $\theta=3 / \omega$ is the utilization elasticity of the labor costs.

ting that the labor elasticity of the labor costs is unity, equation (8) illustrates, in the short run, that the ratio of cost elasticities equals the ratio of revenue elasticities. If the labor elasticity of revenue exceeds that for utilization, then the utilization elasticity of costs is less than unity. The firm, in this situation, operates on the inelastic portion of the premium rate. For the firm to operate on the elastic segment, we must have $e_{\beta}>e_{\ell} 6^{6}$

We are interested in establishing the response of labor requirements and $P \& E$ utilization to changes in the capital stocks and the scale real wage. If the stock of $P \& E$ in $R \& D$ intensive form increases, the effect on the utilization rate is ${ }^{7}$

$$
\frac{\partial \beta}{\partial k_{p}}=-\frac{p^{2} f_{22} f_{1}}{H}\left(e_{B \beta}+1\right)+\frac{p^{2} k_{p} f_{21} f_{1}}{H \ell}\left(e_{B \ell}-1\right) .
$$

The Legendre-Clebsch conditions imply that net operating revenues in $R \& D$ intensive form $\pi / K_{r}=p f\left(\beta k_{\beta} \ell\right)-s \omega(\beta) \ell$ is strictly concave in $\beta$ and $\ell$. Hence the Hessian determinant (II) in equation ( 9 ) is positive. In addition, sufficient conditions for $H>0$ (besides $\omega^{\prime \prime}>0$ ) are $e_{B \beta}<\min (-1,-\theta)$, and $e_{B \ell}<1+\min \left(e_{\ell \ell}, e_{\ell \ell} / \theta\right)$. The former condition means that the marginal product of $P \& E$ utilization must diminish in sufficient magnitude as $\beta$ rises, while the latter condition implies that the same marginal product must be limited in its increase as 2 rises.

Another way to interpret these two conditions can be obtained from equation (7.2). We see the difference between the value of the marginal product and the marginal input cost for utilization depends on $\xi$ and $\&$. 
The restriciton on $e_{\beta \beta}$ guarantees that the difference decreases as $\beta$ $i$ creases and the restriction on $e_{\beta \ell}$ ensures that the difference decreases as $\ell$ increases. Clearly, with these two conditions, the right side of (9) is negative. As $k_{p}$ expands, because of the change in the marginal product of P\&E utilization, two effects are initiated. The first can be termed the "own effect." The larger $k_{p}$ causes the value of the marginal product of utilization to diminish such that it is now below the marginal input cost of utilization. The second effect (the "cross effect") emanates from the fact that the value of the marginal product of labor is now below the respective marginal input cost. In order to restore equilibrium, the $P \& E$ utilization rate must decrease.

The decrease in the rate of utilization, which decreases the wage bill at each unit of labor services, and the increase in marginal product of 1 abor from an expansion of $k_{p}$, cause labor in R\&it intensive form to . rise. This is seen from

$$
\frac{\partial l}{\partial k_{p}}=\frac{p^{f} 21^{\beta}}{\tilde{H}}\left[p f_{11} k^{2}-s \omega^{\prime \prime} \ell\right]+\frac{p^{2} f_{1}^{2} k}{H l}\left(e_{B \beta}+1\right)\left(e_{B \beta}-1\right)>0 .
$$

Hence as $k_{p}$ decreases the firm becomes less labor intensive in the short run. This result occurs, not in the usual sense of changing the plant and equipment to labor ratio, but rather, because the ratio of the $P \& E$. utilization rate to labor in $R \& D$ intensive form rises. As $R \& D$ expands relative to $P \& E$, labor relative to $R \& D$ falls and the utilization rate rises.

The scale real wage also creates a divergence in the magnitudes of employment and utilization. In our context an increase in the basic 
real wage $\mathbf{s}$ leads to a decrease in labor requirements and an increase ir P\&E utilization. Differentiating (7.1) and (7.2) with respect to $\mathrm{s} / \mathrm{p}$ yields

$$
\frac{\partial \ell}{\partial(s / p)}=-\frac{\omega s \omega^{\prime \prime} \ell}{H_{1} p}-\frac{\omega^{\prime} k_{p} f_{1}}{H_{1}} e_{B \ell}+\frac{k_{p} f_{1}}{H_{1} \beta}\left(e_{B \beta}+\theta\right)<0
$$

and

$$
\frac{\partial \beta}{\partial(s / p)}=-\frac{\omega f_{2} \theta}{H_{1} \beta}\left(e_{\beta \ell}-e_{\ell \ell}-1\right)>0,
$$

where $H_{1}=H / p^{2}$.

Summarizing the short run results for $\beta$ and $\ell$ from equations (9) to (12) we can define

$$
\begin{array}{ll}
B=B\left(k_{p}, s / p\right) & B_{1}<0, B_{2}>0 \\
\ell=G\left(k_{p}, s / p\right) & G_{1}>0, G_{2}<0 .
\end{array}
$$

Finally, in the short run, from equations (7.3) and (7.4) we find that both types of investment rates respond in a positive fashion to increases in their respective demand prices. Thus,

$$
I_{p} / K_{p}=J_{p}\left(q_{1}\right)
$$

where $I_{P}^{\prime}=1 / C^{\prime \prime} \frac{I_{p}}{K_{p}}+2 C^{\prime}>0$, and

$$
I_{r} / K_{r}=I_{r}\left(q_{2}\right)
$$

where $\mathfrak{J}_{r}^{\prime}=1 / E^{\prime \prime} \frac{I_{r}}{K_{r}}+2 E^{\prime}>0$. These later results are similar to those 
found in ould [1968], Lucas [1967] and Treadway [1969]. The investment decisions illustrate the intertemporal link as the investment-capital ratios depend on the demand prices, which are equal to the present value of the rentals accruing to units of the capital stocks installed at time $t$ but brought into service over the remaining time horizon.

\section{Dynamics and the Steady State}

Given the short run solution we are now in a position to analyze the intertemporal path of the firm and the steady state equilibrium. Substituting equations (13.1), (13.2), (14) and (15) into (7.5) - (7.8) yields the dynamic behavior as

$$
\begin{aligned}
\dot{\mathrm{K}}_{\mathrm{p}} / \mathrm{K}_{\mathrm{p}} & =\mathrm{J}_{\mathrm{p}}\left(\mathrm{q}_{1}\right)-\delta \\
\dot{\mathrm{K}}_{\mathrm{r}} / \mathrm{K}_{\mathrm{r}} & =\mathrm{J}_{\mathrm{r}}\left(\mathrm{q}_{2}\right)-\eta \\
\dot{\mathrm{q}}_{1} & =(\mathrm{r}+\delta) \mathrm{q}_{1}-\mathrm{pf}_{1}\left[\mathrm{~B}\left(\mathrm{k}_{\mathrm{p}}, \mathrm{s} / \mathrm{p}\right) \mathrm{k}_{\mathrm{p}}, \mathcal{G}\left(\mathrm{k}_{\mathrm{p}}, \mathrm{s} / \mathrm{p}\right)\right] \mathrm{B}\left(\mathrm{k}_{\mathrm{p}}, \mathrm{s} / \mathrm{p}\right) \\
& -\mathrm{C}^{\prime}\left[\mathrm{J}_{\mathrm{p}}\left(\mathrm{q}_{1}\right)\right]\left[\mathrm{J}_{\mathrm{p}}\left(\mathrm{q}_{1}\right)\right]^{2}
\end{aligned}
$$

$$
\begin{aligned}
\dot{q}_{2}= & (r+\eta) q_{2}-p f\left[B\left(k_{p}, s / p\right) k_{p}, G\left(k_{p}, s / p\right)\right] \\
& +p f_{1}\left[B\left(k_{p}, s / p\right) k_{p}, G\left(k_{p}, s / p\right)\right] k_{p} B\left(k_{p}, s / p\right) \\
& +p f_{2}\left[B\left(k_{p}, s / p\right) k_{p}, G\left(k_{p}, s / p\right)\right] G\left(k_{p}, s / p\right) \\
& -E^{\prime}\left[J_{r}\left(q_{2}\right)\right]\left[J_{r}\left(q_{2}\right)\right]^{2}
\end{aligned}
$$

Let us proceed by first analyzing the intertemporal paths of the capital stocks. Clearly, from (16) and (17) the rate of growth of P\&E and $R \& D$ depend only on their respective demand prices and depreciation 
rates. lence, by noting that $\dot{\mathrm{k}}_{\mathrm{p}}=\mathrm{k}_{\mathrm{p}}\left(\dot{\mathrm{k}}_{\mathrm{p}} / \mathrm{K}_{\mathrm{p}}-\dot{\mathrm{K}}_{\mathrm{r}} / \mathrm{K}_{\mathrm{r}}\right)$, we can combine (16) and (17) into a single equation illustrating the evolution of the ratio of the capital stocks. This mean that changes in $k_{p}$ depend on $q_{1}$, and $q_{2}$, such that $\frac{\partial \dot{k}}{\partial q_{1}}=k_{p} J_{p}>0$ and $\frac{\partial \dot{k}}{\partial q_{2}}=-k_{p} J_{r}^{\prime}<0$ (for $k_{p}>0$ ). Therefore, with $\dot{k}_{p}=0$ we have a locus in $\left(q_{2}, q_{1}\right)$ space (see Figure 1 ) which is positively sloped, since

$$
\left.\frac{\mathrm{dq}}{d q_{2}}\right|_{k_{p}=0}=\frac{J^{\prime}}{\mathfrak{J}_{p}^{\prime}}>0
$$

The $\dot{\mathrm{k}}_{\mathrm{p}}=0$ curve shows us that in order to maintain the equality between the growth rates for plant and equipment and research and development both investment demand prices must rise thereby generating increases in investment rates for both types of capital. Moreover, if the demand price of $\operatorname{P\& E}\left(q_{1}\right)$ is above that defined by the $\dot{k}_{p}=0$ locus for any value of $q_{2}$, then the $P \& E$ investment rate outruns the rate for $R \& D$, causing $\dot{\mathrm{k}}_{\mathrm{p}}>0$. The converse occurs for values of $\mathrm{q}_{2}$ below the $\dot{\mathrm{k}}_{\mathrm{p}}=0$ curve. Turning to the price equations $[(18)$ and (19)] we find that changes in the prices over time are governed by the difference between the net marginal input cost and the value of the marginal product. In terms of plant and equipment, the net marginal input cost is $(r+\delta) q_{1}$, minus the reduction in adjustment cost from increasing $\mathrm{K}_{\mathrm{p}}$ which is $C^{\prime}\left(I_{p} / K_{p}\right)^{2}$, while the value of the marginal product is $p f_{1} \beta$. Clearly, if the net marginal input cost exceeds the value of the marginal product, then in order for the firm to remain in short rin equilibrium, there must be a capital gain on the asset. Thus an increase in the price of a 


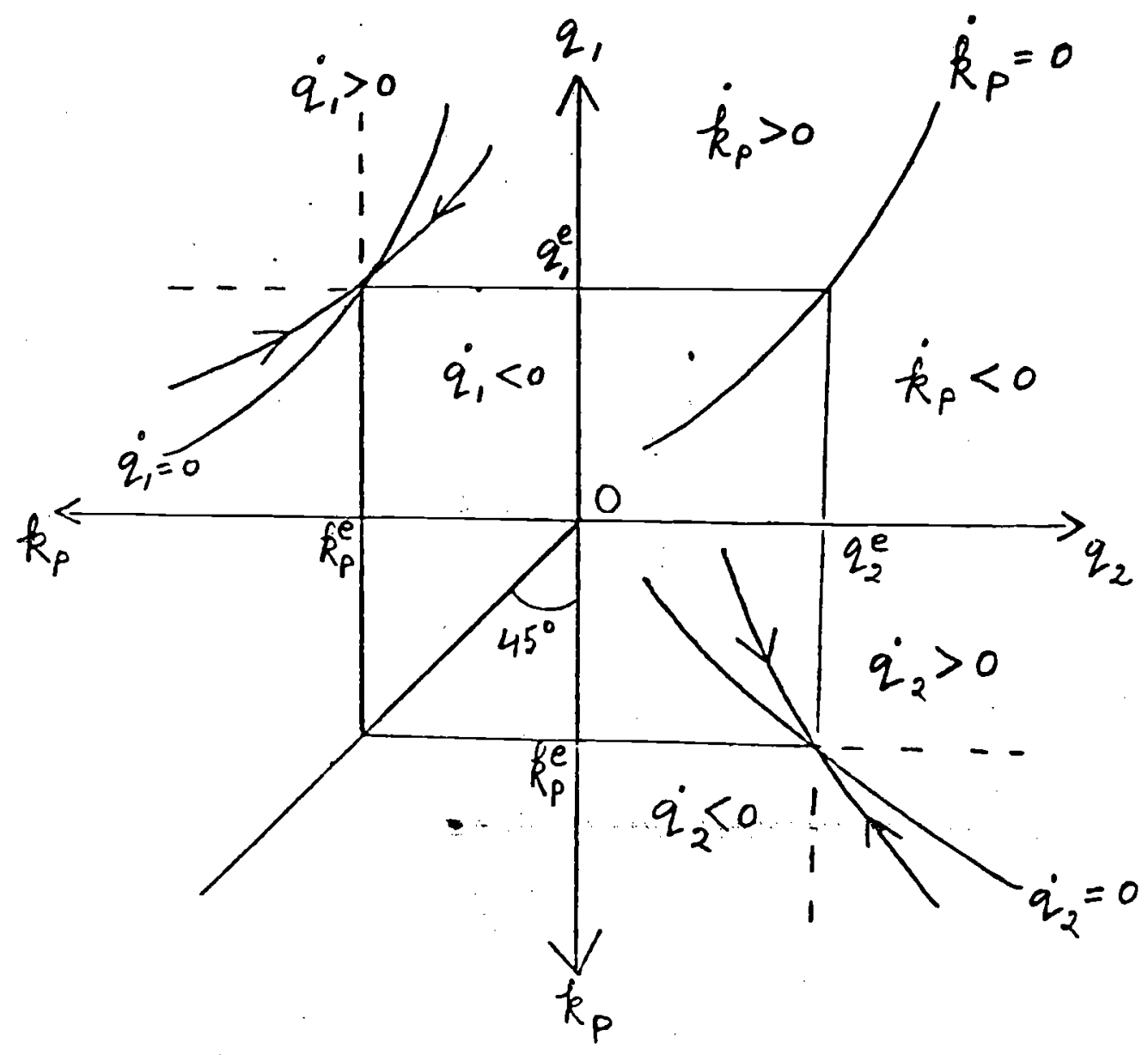


machine leads to an increase in the net marginal input cost and therefore a capital gain accrues to the firm. From equation (18),

$$
\frac{\partial \dot{q}_{1}}{\partial q_{1}}=r+\delta-I_{p} / K_{p}
$$

the right side of which, in the neighborhood of $\dot{k}_{p}=0$, is positive since the rates of growth of both types of capital must be less than the discount rate, in order for the present value of the flow of funds to be finite.

The effect of an increase in the $P \& E$ to $R \& D$ ratio is

$$
\frac{\partial \dot{q}_{1}}{\partial k_{p}}=-p f_{11}\left[B_{1} k_{p}+\beta\right] \beta-p f_{1} B_{1}-p f_{12} f_{1} .
$$

In order to sign the right side of (22) consider the net operating revenue function per unit of $R \& D, p f\left(\beta k_{p}, l\right)-\omega(\beta) l$. By the LegendreClebsch conditions this function is strictly concave in $\beta$ and $\ell$.

In addition, the production function $\left[f\left(\beta k_{p}, l\right)\right]$ is strictly concave in $\beta k_{p}$ and $\ell$ then net operating revenues per unit of $R \& D$ is strictly concave in these two variables. Thus the Hessian, with respect to $\beta, \ell$ and $k_{p}$, is negative definite. Equivalently the principal minors of

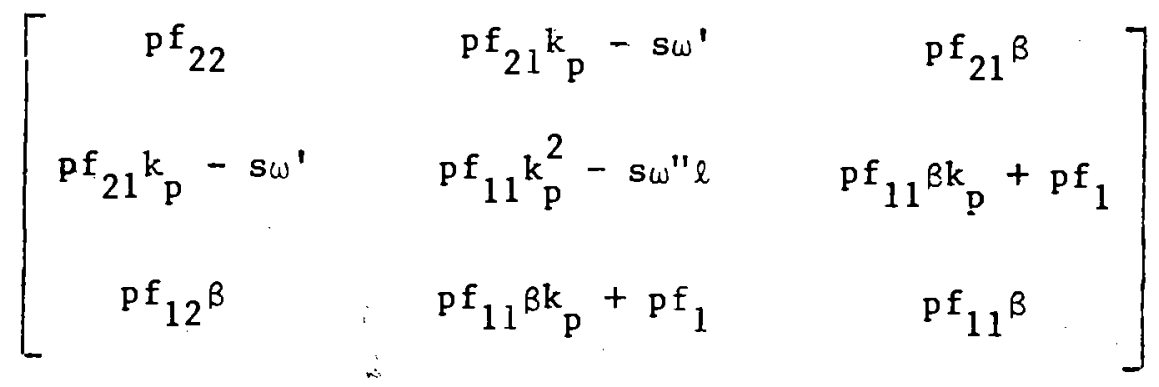


alternate in sign with $\mathrm{pf}_{22}<0, \mathbb{H}>0$ and the determinant $H_{2}<0$. By s. stituting for $B_{1}$ and $G_{1}$ from equations (13.1) and (13.2), the right side of (22) becomes

$$
\frac{\partial \dot{q}_{1}}{\partial \mathrm{k}}=-\frac{\mathrm{H}_{2}}{\mathrm{H}}>0
$$

An increase in the stock of $R \& D$ raises the value of the marginal product of $P \& E$, the firm must absorb a capital loss in order to remain in short run equilibrium. Combining the results from (21) and (23) yields the $\dot{q}_{1}=0$ locus in $\left(k_{p}, q_{1}\right)$ space in Figure 1 , which is negatively sloped, since $\left.\frac{\mathrm{dq}_{1}}{\mathrm{dk}}\right|_{\mathrm{p}}=\frac{\mathrm{H}_{2}}{\dot{\mathrm{q}}_{1}=0} \mathrm{H}_{\mathrm{k}}\left[\mathrm{r}+\delta-\left(\mathrm{I}_{\mathrm{p}} / \mathrm{K}_{\mathrm{p}}\right)\right]<0$, and points above the curve show $\dot{q}_{1}>0$ and below the curve $\dot{q}_{1}<0.8$

A similar set of results holds for the demand price of R\&D. We find that $\frac{\partial \dot{q}_{2}}{\partial q_{2}}=r+n-I_{r} / K_{r}>0$ when the evaluation is at $\dot{q}_{2}=0=\dot{k}_{p}$ and $\frac{\partial \dot{q}_{2}}{\partial k_{p}}=k_{p} H_{2} / H<0$. An increase in the stock of $R \& D$ decreases the value of the marginal product and therefore a capital gain must accrue to the firm. Thus, we find a locus $\dot{q}_{2}=0$ which is positively sloped in $\left(k_{p}, q_{2}\right)$ space in Figure 1 , with points above the curve defining $\dot{q}_{2}>0$ and below $\dot{q}_{2}<0$.

Using the four quadrant technique developed by Abel [1981] we can characterize the steady state solution $\left(\dot{k}_{p}=0=\dot{q}_{1}=\dot{q}_{2}\right)$ for the firm 
from $\left(F_{\left.i g u_{+}-1\right)}\right.$ at $\left(k_{p}^{e}, q_{1}^{e}, q_{2}^{e}\right)$. There exists a unique steady state which

$s$ a saddle point. The steady state values are denoted by the formation of the rectangle and the dynamic paths are monotonic and illustrated in $\left(k_{p}, q_{1}\right)$ and $\left(k_{p}, q_{2}\right)$ spaces. 9 Although the graphical nature of the steady state is similar to Abel [1981], the path to long run equilibrium is quite distinct.

From Figure 1 we can characterize the nature of the path that the firm follows to the steady state. The paths of $k_{p}, q_{1}$ and $q_{2}$ are illustrated in the northwest and southeast quadrants. Suppose that $\mathrm{k}_{\mathrm{p}}<\mathrm{k}_{\mathrm{p}}^{\mathrm{e}}$; then we find $\mathrm{q}_{1}>\mathrm{q}_{1}^{\mathrm{e}}$ and $\mathrm{q}_{2}<\mathrm{q}_{2}^{\mathrm{e}}$. From the results on the dependence of utilization, labor and investment demand [equations (13) (15)], $\beta>\beta^{e}, \ell<\ell^{e}, I_{p} / K_{p}>\left(I_{p} / K_{p}\right)^{e}$ and $I_{r} / K_{r}<\left(I_{r} / K_{r}\right)^{e}$. If the plant and equipment in R\&D intensive terms is below its steady state solution then P\&E utilization and growth rates are above, while labor per unit of $R \& D$ and the $R \& D$ growth rate are below their respective long run solutions.

Intuitively, when $k_{p}<k_{p}^{e}$, in order for this ratio to increase, the firm must be investing in $P \& E$ at a higher rate and investing in $R \& D$ at a lower rate than necessary to sustain the steady state. Simultaneously, the existing $P \& E$ is utilized excessively. This means that the $P \& E$ utilization rate is above its long run level because the firm is forced to "squeeze" production into the smaller stock. Moreover, because there is a smaller stock of $P \& E$ to $R \& D$, there is less of a need for 1 abor and consequently labor to $R \& D$ requirements are below their steady state level. The converse arises when $k_{p}>k_{p}^{e}$. 
In $\quad$ model, the physical capital utilization and growth rates are positively correlated over time, while labor and R\&D investment per unit of the stock of knowledge both move in the same direction. These results seem quite significant. First, the stylized facts (see Foss [1981]) are that when the P\&E utilization rate rises, the investment rate must rise in order to ease the pressure on the stock. Clearly, we have provided a framework which establishes this relationship.

This result is the opposite to that found in Abel [1981] and it illustrates a major difference in the treatment of utilization. Abel does not deal with the problem of $R \& D$, and he treats labor as a quasifixed factor. In his framework, capital utilization directly depends on labor utilization, and it is only the latter which is costly to use. Consequently, with increases in labor decreasing the value of the marginal product of labor utilization, the firm must decrease the utilization rate in order to restore short run equilibrium. Therefore, labor utilization and capital utilization (since it is directly dependent on the forner) increase as the capital-labor ratio rises. There is a negative correlation between the utilization and the investment rate. This result turns on the assumption that only labor utilization is costly.

In our context labor is a variable factor and therefore is costly to use. Indeed, the marginal input cost is $s w$. However, the crucial element is that $P \& E$ is also costly to use. In fact, the marginal input cost, which is $s w^{\prime} L$, manifests itself in a higher wage bill.

The second major conclusion concerning the nature of the dynamic path is that labor in $R \& D$ intensive form and the $R \& D$ growth rate are positively correlated. This result means that as the ratio of labor 
to the stoc the R\&D growth rate must rise accordingly. Recall that in the short run if $R \& D$ expands relative to $P \& E$ then labor in $R \& D$ intensive form lecreases. This conclusion arises only if the intertemporal dimension is ignored. In a dynamic setting the stock of knowledge is not given to the firm but it is endogenously accumulated. Indeed, it is the rising R\&D growth rate which allows labor requirements to grow relative to the stock of knowledge. Hence we can characterize the rising $P \& E$ investment rate as $P \& E$ utilizing and the rising $R \& D$ investment rate as labor using. 10

\section{Comparative Steady States}

In this section we consider the effects of changes in the discount rate, depreciation rates and the product price on the long run equilibrium.

Suppose that the discount rate increases. From equations (18) and (19) we observe that the marginal input costs of $P \& E$ and R\&D increase. Thus, at the original steady state, in order to maintain $\dot{q}_{1}=\dot{q}_{2}=0$ the investment demand prices must fall, thereby lowering marginal input costs to their original levels. However, as both $q_{1}$ and $q_{2}$ decrease, $k_{p}$ responds in an ambiguous fashion because both investment-capital ratios are declining. Therefore, the impact on $k_{p}$ is unknown and consequently the actual magnitude of the changes in $q_{1}$ and $q_{2}$ are not exactly proportional to the change in the discount rate. These results can be derived by combining equations (16) and (17) and differentiating the three resulting long run equilibrium conditions to yield 
(3) $\frac{\partial q_{1}}{\partial r}=-k_{p} \frac{j H_{r} H_{2}}{H_{3}}\left(q_{2}+q_{1} k_{p}\right)<0$

where $\mathbb{H}_{3}<0$ is the relevant hessian determinant and $\frac{\partial q_{2}}{\partial r}=\mathfrak{J}_{p}^{\prime} \frac{\partial q_{1}}{\partial r} / \mathfrak{J}_{r}^{\prime}<0$, while $\frac{\partial k}{\partial r}=\frac{I_{p}}{K_{p}}-\delta \frac{k}{\mathbb{H}_{3}}\left[\mathcal{J}_{p}^{\prime} q_{1}-J_{r}^{\prime} q_{2}\right]$, the sign of which is clearly ambiguous and depends on the relative responsiveness of the investmentcapital ratios to their respective demand prices. ${ }^{11}$

Next suppose that there is an autonomous change in the depreciation rate on research and development; that is, knowledge becomes obsolete at a faster rate. In this instance there is a shift towards the capital stock with the relative increase in its life, which means that the plant and equipment to research and development capital ratio rises. The increase in $k_{p}$ lowers the value of the marginal product for P\&E, therefore the demand price $\left(\mathrm{q}_{1}\right)$ must fall in order to bring into line the marginal input cost. Lastly, for this experiment, the demand price for $R \& D$ is subject to two opposing forces. The increase in $n$ at the initial $k_{p}$ causes $q_{2}$ to diminish to retain the constancy of the marginal input cost to the unchanged value of the marginal product of $R \& D$.

However, as $k_{p}$ rises the value of the marginal product of R\&D increases and this shifts the burden of adjustment away from the price and onto the stock. Formally,

$$
\frac{\partial q_{1}}{\partial \eta}=-\frac{H_{2}}{\mathfrak{H}_{3} H^{\prime}}\left(n+q_{2} k_{p} \mathfrak{x}_{r}^{\prime}\right)<0
$$

and $\frac{\partial \mathrm{k}_{\mathrm{p}}}{\partial \eta}=\frac{\mathrm{H}_{3}}{\mathrm{H}_{2}} \mathrm{n} \frac{\partial \mathrm{q}_{1}}{\partial \eta}>0, \frac{\partial \mathrm{q}_{2}}{\partial \eta}=\frac{\mathrm{H}_{2}}{\mathfrak{H}_{3} \mathrm{H}^{\mathrm{h}}} \mathrm{k}_{\mathrm{p}}\left(\mathrm{n}-\mathrm{q}_{2} \mathrm{~J}_{\mathrm{p}}^{\prime}\right) .12$ 
The final change we consider is the effect of an increase in the product price. By inspection the capital accumulation equations [(16) and (17)] are not directly affected by the product price. However, from the investment demand price equations

$$
\begin{aligned}
\frac{\partial \dot{q}_{1}}{\partial p}= & -f_{1} \beta+G_{2} s_{1} \beta f_{12} / p+B_{2} \mathrm{sf}_{1}\left(e_{\beta \beta}+1\right) / p<0 \\
\frac{\partial \dot{q}_{2}}{\partial p}= & -f\left(1-e_{\beta}-e_{\ell}\right)-B s / p k_{p}\left(f_{11} \beta k_{p}+f_{21} \ell\right) \\
& -G s / p\left(f_{22} l+f_{12} \beta k_{p}\right) .
\end{aligned}
$$

Some ambiguity arises in this situation as $\frac{\partial \dot{q}_{2}}{\partial p} \gtreqless 0$. However, since

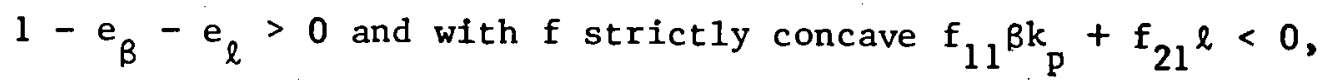
$\mathrm{f}_{22^{\ell}}+\mathrm{f}_{12^{\beta k}}<0$, then if an increase in the scale raal wage sufficiently reduces the labor to $R \& D$ rate and does not materially increase the P\&E utilization rate (i.e., the own effect dominates the cross effect) then there is a presumption that $\frac{\partial q_{2}}{\partial p}<0$. Using the results from (26) and (27) and differentiating the dynamic equations with respect to $\mathrm{p}$ yields

$$
\frac{\partial k_{p}}{\partial p}=\frac{k_{p} n}{\mathcal{H}_{3} n}\left(\mathcal{J}_{p}^{\prime} \frac{\partial \dot{q}_{1}}{\partial p}-\mathcal{J}_{r}^{\prime} \frac{\partial \dot{q}_{2}}{\partial p}\right) .
$$

If $\frac{\partial \dot{q}_{2}}{\partial p} \geq 0$ then $\frac{\partial k p}{\partial p}>0$. If the increases in the product price cause $R \& D$ to grow relatively more than $P \& E$, then the marginal input cost exceeds the value of the marginal product for $R \& D$ and a capital gain must accrue to the firm (i.e., $\dot{q}_{2}$ increases). Moreover, with the 1 arger $k_{p}$, 
we deduce from the short run demand functions that the firm decreases the utilization rate while increasing labor per unit of R\&D capital.

Continuing to the investment demand prices,

$$
\frac{\partial q_{1}}{\partial p}=-\frac{k_{p} \mathfrak{J}_{r}^{\prime} \mathfrak{H}_{2}}{\mathfrak{H}_{3} \mathfrak{H}}\left(\frac{\partial \dot{q}_{2}}{\partial p}+k \frac{\partial \dot{q}_{1}}{\partial p}\right)=\frac{\mathfrak{J}_{p}^{\prime}}{\mathfrak{J}_{r}^{\prime}} \frac{\partial q_{2}}{\partial p}
$$

If $\frac{\partial \dot{q}_{2}}{\partial p} \leq 0$ then $\frac{\partial q_{1}}{\partial p}>0, \frac{\partial q_{2}}{\partial p}>0$ and so the investment capital ratios increase. What is important about this exercise is that changes in the product price elicit ambiguous results. The knife edge case $\left(\frac{\partial \dot{q}_{2}}{\partial p}=0\right)$ where ambiguity ceases illustrates that increases in the product price lead to a smaller steady state value of $\beta$ and larger steady state value of $\ell, I_{p} / K_{p}$ and $I_{r} / K_{r}$. However, the crucial element is that along the dynamic path two direct relationships exist. The first is between the

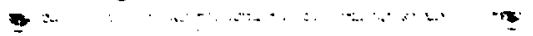
utilization and the $P \& E$ growth rates and the second relates the ratio of labor to $R \& D$ and the R\&D growth rate. The fact that with a higher price the ultimate value of $\beta$ may be smaller and the ultimate value of $I_{p} / K_{p}$ larger, only informs us about the characteristic of the steady state.

\section{Conclusion}

In this paper we have developed a dynamic analysis of a firm undertaking plant and equipment and research and development investment, along with labor requirement and P\&E utilization decisions. We have established that in the short run increases in R\&D cause the firm to increase the $P \& E$ utilization rate while decreasing its demand for labor per unit of $R \& D$. In addition, increases in the real scale wage rate 
cause the firm to substitute physical capital utilization for labor. The dynamic path of the firm was characterized as one where the utilization and investment rates for plant and equipment are positively related, while investment in $R \& D$ and labor per unit of R\&D are simflarly related. The latter conclusion illustrates the importance of distinguishing between the stock of R\&D and the investment flow. The short run effect of changes in the fixed stock of R\&D on labor demand are quite distinct from the behavior observed along the intertemporal path. Along the path increases in the R\&D investment rate must be accompanied by an Increase in the labor requirement per unit of R\&D. Contrary to a viewpoint held by many, the R\&D Investment flow does not displace labor. Finally, the direct relationship between the utilization and the P\&E investment rates illustrates that our framework can be used to justify this empirical observation. 


\section{Footnotes}

1. We can easily generalize our results to allow a variable utilization rate on $R \& D$. Suppose this rate is $\gamma$ and $\gamma=\Gamma\left(\beta_{\gamma} \Gamma^{\prime} \geq 0\right.$, $\Gamma(0)=0$. ' In the paper $\Gamma^{\prime}=0$ and $\gamma$ is normalized to unity. In equation (1) the utilization elasticity of output equals the P\&E elasticity of output, as in. Nadiri and Rosen [1969].

2. The function $\omega(\beta)$ is the premiun lage function found in Lucas [1970]. It is designed to capture the rising labor payment as the hours the P\&E is operated moves from the most to the least attractive.

3. We delete the variable $(t)$ for notational simplicity. The results in this paper also hold when the firm is a monopolist in the product market, with the inverse product demand function $p=D(y), D^{\prime}<0$.

4. Adjustment costs are by now quite standard; see Lucas [1969], Mussa [1977], Treadway [1970].

5. We define $e_{\beta}=\mathrm{f}_{1} \beta \mathrm{k}_{\mathrm{p}} / \mathrm{f}>0$ as the utilization elasticity of output and $e_{\ell}=f_{2} l / f>0$ as the labor elasticity of output. In addition, $\mathrm{e}_{\beta \beta}=\mathrm{f}_{11} \mathrm{k}_{\mathrm{p}} \beta / \mathrm{f}_{1}<0, \mathrm{e}_{\ell \ell}=\mathrm{f}_{22} \ell / \mathrm{f}_{2}<0$ and $\mathrm{e}_{B \ell}=\mathrm{f}_{12} \ell / \mathrm{f}_{1}$.

6. In Abel [1981] the firm must operate on the elastic portion of the function $\omega(\beta)$ because (using our context) the production function is $y=F\left(\beta K_{p}, \beta K_{r} ; L\right)$. If $\mathrm{f}$ is homogeneous of degree 1 then $y=\beta K_{r} f\left(k_{p}, l\right)$. Thus, utilization affects output in proportion to output obtained from the full utilization of the capital stocks $\left[k_{r} f\left(k_{p}, l\right)\right]$. This implies that the utilization elasticity of revenue is unity and so equation (8) becomes $\theta=1 / e_{\ell}>1$, since $e_{\ell}>1$. The firm in this case must operate or the elastic portion of the premium rate. The production function in our model allows for a variable utilization elasticity of production and thereby also for revenue. 
7. We now introduce the usual assumption that $\mathrm{f}_{12}>0$. An increase in $\beta k_{p}$ increases the marginal product of labor. Therefore, $e_{B l}>0$.

8. We ignore the fact that $\frac{\partial \dot{q}_{1}}{\partial q_{1}}$ can be nonpositive where $\dot{k}_{p} \neq 0$.

9. The revelant boundary conditions on the production function prevent $k_{p}^{e}$ (the steady state solution) and thereby $q_{1}^{e}$ and $q_{2}^{e}$ from being either 0 or $\infty$.

10. We see the importance of a dynamic formulation of the R\&D decision. In a static framework we would not be able to distinguish between the stock of $R \& D$ and the investment flow.

11. $H_{3}=k_{p} n \frac{H_{2}}{H}\left(\mathfrak{J}_{p}^{\prime}+k_{p} J_{r}^{\prime}\right)<0$ and $n=r+\delta-J_{p}^{\prime}=r+n-J_{r}^{\prime}$. 12. The results for an increase in $\delta$ follow from the effects of an increase in $n$. We find that $k_{p}$ and $q_{2}$ decilne while the change in $q_{1}$ is ambiguous. 


\section{References}

Abe1, Andrew B., "A Dynamic Model of Investment and Capac1ty Ut1lizat1on," Quarterly Journal of Economics (Aug. 1981), 379-403.

, Investment and the Value of Cap1tal (New York: Garland

Publishing, Inc., 1979).

Denison, Edward F., Accounting for United States Growth, 1929-1969

(Washington, D.C.: Brookings Institution, 1974).

Foss, Murray F., "Long-Run Changes in the Workweek of Fixed Capital,"

American Economic Peview Papers and Proceedings, I,YKI (May 1981), 58-63.

Gould, John P., "Adjustment Costs in the Theory of Investment of the Firm," Review of Economic Studies, XXXV (Jan. 1968), 47-55.

Jorgenson, Dale W., "Capital Theory and Investment Behavior," American

Economic Review Papers and Proceedings, LIII (May 1963), 247-259.

Jorgenson, Dale, and Zvi Griliches, "The Explanation of Productivity

Cnange," Review of Economic Studies, XXXIV (July 1967), 249-282.

Kendrick, John W., Postwar Productivity Trends in the U.S., 1948-1969

(New York: Columbia University Press, 1973).

Lucas, Robert E., Jr., "Optimal Investment Pollcy and the Flexible

Accelerator," International Economic Review, VIII (Feb. 1967), $78-85$.

—_, "Capacity, Overtime and Empirical Production Functions," American Economic Review Papers and Proceedings, LX (May 1970), $23-27$. 
Mansfieid, Edwin, "Contribution of Research and Development to Economic

Growth of the United States," Papers and Proceedings of a

Colloguium: Research and Development and Economic Growth

Productivity (Washington, D.C.: National Sclence Foundation, U.S. Government Printing Office, 1972).

Mussa, Michael, "External and Internal Adjustment Costs and the Theory of Aggregate and Firm Investment," Ecbnomica, XIIV (May 1977), 163-178.

Nadiri, M. Ishaq, and Sherwin Rosen, "Interrelated Factor Demand Functions," American Economic Review, LIX (Sept. 1969), 457-471. - A Disequilibrium Model for Factors of Production (New York: Columbia University Press, 1973).

Taubman, Paul and Maurice Wilkinson, "User Cost, Capital Utilization and Investment Theory," International Economic Review, 11 (June 1970), 209-215.

Treadway, Arthur B., "On Rational Entrepreneurial Behavior and the Demand for Investment," Review of Economic Studies, XXXVI (1969), 227-239. - "Adjustment Costs and Variable Inputs in the' Theory of the Competitive Firm," Journal of Economic Theory, 11 (1970(, 329-347. Winston, Gordon, C., "The Theory of Capital Utilization and Idleness,", Journal of Economic Literature, XII (Dec. 1974), 1301-1302.

Winston, Gordon C., and Thomas O. McCoy, "Investment and the Optimal Idleness of Capital," Review of Economic Studies, XLI (July 1974), 419-428. 